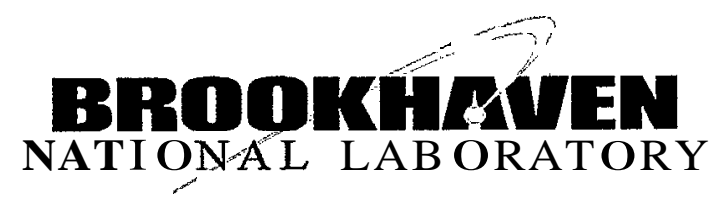

BNL-73483-2005-CP

\title{
Linearizing The Response of the NSRL Synchronous Recycling-Integrators
}

\author{
P. Oddo, A. Rusek, T. Russo \\ Presented at the Particle Accelerator Conference(PAC'05) \\ Knoxville, Tennessee \\ May 16-20,2005
}

\author{
Collider-Accelerator Department \\ Brookhaven National Laboratory \\ P.O. Box 5000 \\ Upton, NY 11973-5000 \\ www.bnl.gov \\ Managed by \\ Brookhaven Science Associates, LLC \\ for the United States Department of Energy under \\ Contract No. DE-AC02-98CH10886
}

\begin{abstract}
This is a preprint of a paper intended for publication in a journal or proceedings. Since changes may be made before publication, this preprint is made availablewith the understandingthat it will not be cited or reproduced without the permission of the author.
\end{abstract}




\title{
DISCLAIMER
}

This report was prepared as an account of work sponsored by an agency of the United States Government. Neither the United States Government nor any agency thereof, nor any of their employees, nor any of their contractors, subcontractors, or their employees, makes any warranty, express or implied, or assumes any legal liability or responsibility for the accuracy, completeness, or any third party's use or the results of such use of any information, apparatus, product, or process disclosed, or represents that its use would not infringe privately owned rights. Reference herein to any specific commercial product, process, or service by trade name, trademark, manufacturer, or otherwise, does not necessarily constitute or imply its endorsement, recommendation, or favoring by the United States Government or any agency thereof or its contractors or subcontractors. The views and opinions of authors expressed herein do not necessarily state or reflect those of the United States Government or any agency thereof.

FOR UNCLASSIFIED, UNLIMITED STIPRODUCTS

Available electronically at:

OSTI:

\section{http://www.osti.gov/bridge}

Available for a processing fee to U.S. Department of Energy and its contractors, in paper from:

\author{
U.S. Department of Energy \\ Office of Scientific and Technical Information \\ P.O. Box 62 \\ Oak Ridge, TN 37831 \\ Phone: (865) 576-8401 \\ Facsimile: (865) 576-5728 \\ E-mail: reports@adonis.osti.gov
}

National Technical Information Service (NTIS):

Available for sale to the public from:

U.S. Department of Commerce

National Technical Information Service

5285 Port Royal Road

Springfield, VA 22131

Phone: (800) 553-6847

Facsimile: (703) 605-6900

Online ordering: http://www.ntis.gov/ordering.htm

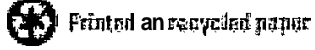




\title{
LINEARIZING THE RESPONSE OF THE NSRL SYNCHRONOUS RECYCLING-INTEGRATORS"
}

\author{
P. Oddo, A. Rusek, T. Russo, BNL, NY 11973-5000, U.S.A
}

\section{Abstract}

The Lawrence Berkeley National Laboratory (LBNL) designed recycling-integrators used for the NASA Space Radiation Laboratory (NSRL) dosimetry feature excellent linearity. However, switching transients in the balancing source add a duty-cycle dependence to the response that manifests as a non-linearity near mid-scale and a slopechange above mid-scale. The onset of this non-linearity limits the typical usable dynamic range. Measurements during a recent run showed that at higher intensities the recycling-integrators would operate in the non-linear region enough to exceed the desired tolerance and over count the dose. This report will show how a FPGA, which implements the scalars, was used to compensate the non-linearity allowing higher dose-rates by effectively doubling the dynamic range of the dosimetry system.

\section{INTRODUCTION}

The NSRL dosimetry system uses 23 LBNL designed 16-channel recycling-integrators (9U VME) cards. They are modified synchronous versions of the recyclingintegrator that were used at the BEVALAC Biomedical Facility. Other modifications include gain and bias DACs as well as the ability to selectively feed an external calibration source to each channel. An onboard "simulated beam" feature will simultaneously drive a $100 \mathrm{nA}$ current (trough the ion-chamber) into all the channels. The recycling-integrators feature a conversion rate of $10 \mathrm{pC} /$ count as well as excellent long-term stability. A Xilinx Spartan-II FPGA implements both a 32-bit scalar and preset-scalar for each channel. Two "real-time sums" are also implemented. Each real-time sum feeds a scalar and preset-scalar with the sum of any combination of the board's 16-channels. The FPGA also performs an "auto-bias" function that maintains an offset of $10 \mathrm{pA}$ or 1 count/sec.

Presently dose cut-off is determined using one of three ion-chambers. Each chamber is made of three foils: a 32 zone concentric-rindquadrant foil, a high-voltage foil, and a 2-zone concentric-ringed foil [1]. Figure 1 shows that the recycling-integrators become non-linear above $3.5 \mu \mathrm{A}$. The large $32 \mathrm{~cm} \times 32 \mathrm{~cm}$ element of the 2 -zone foil regularly operates in this region. Uncorrected the dose would be over counted by more than $10 \%$. So far this element has not been used for dosimetry. Typically a real-time sum of the 4 inner rings of the concentric-ringed foil is used to create the end of dose cut-off. The current

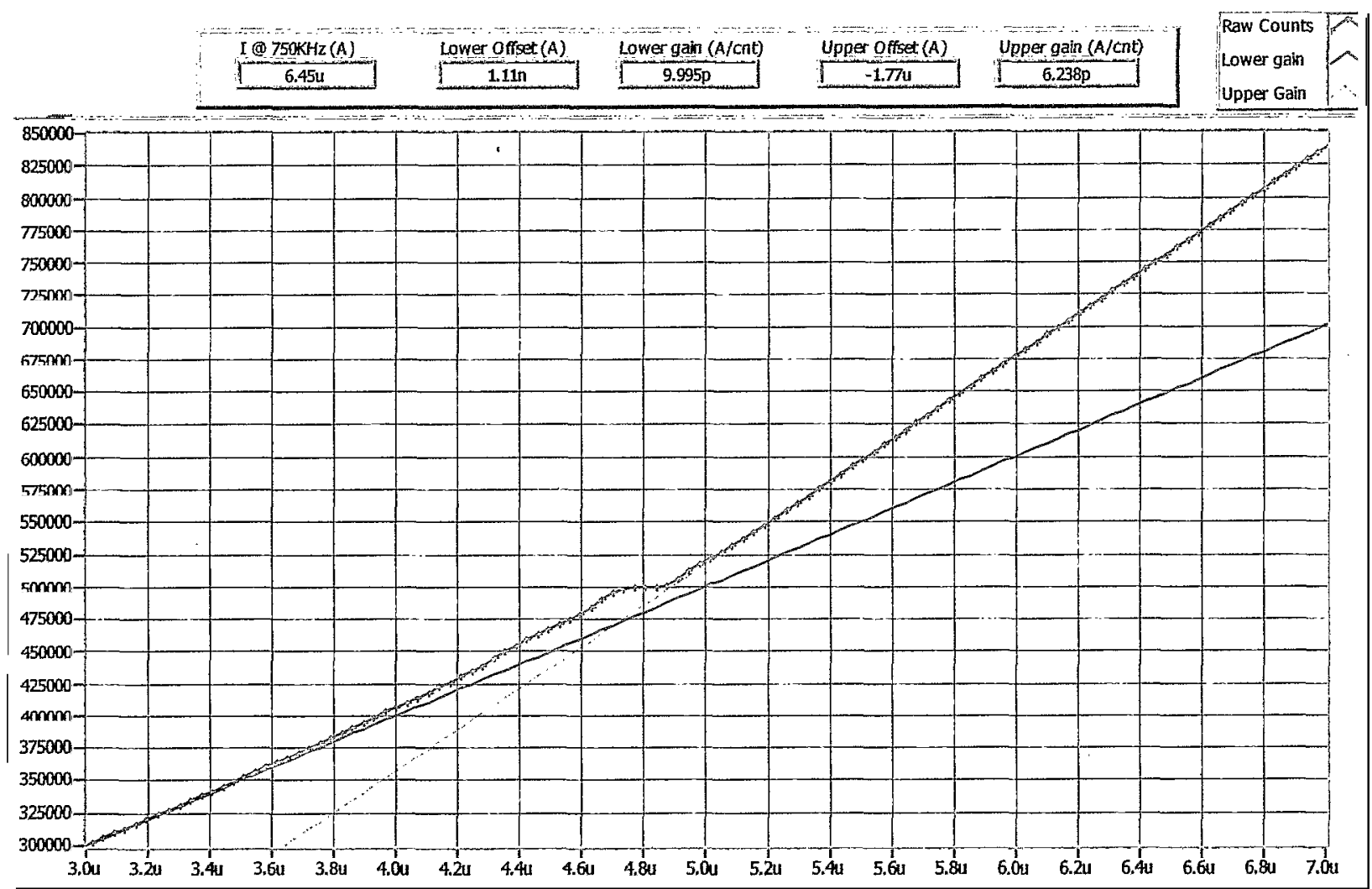

Figure 1:Response of a typical recycling-integratorchannel; the dashed lines illustrate the slope-change. 
from the $4^{\text {th }}$ ring averages $121 \mathrm{nA}$ and therefore has not affected current experiments. Most exposures are done at low intensities (less than $2 \mathrm{~Gy} / \mathrm{min}$ ). At $2 \mathrm{~Gy} / \mathrm{min}$ the $4^{\text {th }}$ ring quadrant current is $301 \mathrm{nA}$. The ion-chambers are not directly used to read dose but are calibrated against an industrially calibrated EG\&G ion-chamber at the sample isocenter [2]. There is also a fourth ion-chamber having 256-elements, arranged as a $16 \times 16$ array, but it is presently not used to create cut-offs.

Since some exposures are done at higher intensities (20$70 \mathrm{~Gy} / \mathrm{min}$ ) it was considered necessary to study the nonlinearity to see at what point and to which extend it affects the dosimetry.

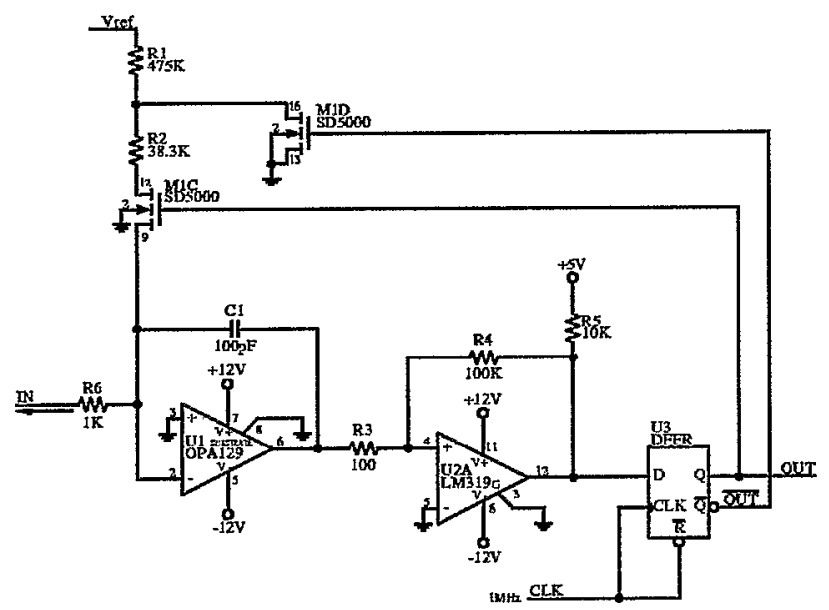

Figure 2: SimplifiedRecycling-Integrator Schematic

\section{RECYCLING INTEGRATOR}

\section{Basic Principles}

A recycling-integrator is charge balance converter also known as a current to fi-equency converter (I/F). Figure 2 shows a simplified schematic of the NSRL recyclingintegrator. This circuit measures negative current flowing out of "IN." A charge-balance converter integrates current (or builds up charge) until a threshold is reached and then fires a balancing current-source for a fixed time to try and bring the total net charge to zero. The integrating capacitance and actual comparator threshold are not that critical, in this case $100 \mathrm{pF}$ and $\mathrm{OV}$ respectively. It's the balancing-source'and the effective balancing charge delivered that is most critical. Ideally this circuit will attempt to deliver $20 \mu \mathrm{A}$ for $500 \mathrm{nS}$ or $10 \mathrm{pC} /$ count. In reality, the charge injected by the MOSFETs during switching and the limited responsetime of the op-amp affects the effective balancing charge significantly (see figures 3 to 5). The parasitic effects limit the maximum clock rate of the recycling-integrator too less than $1 \mathrm{MHz}$. To compensate, the current and pulse-width are both programmable. The clock pulsewidth feeding the flip-flop determines the balancing pulse-width and is global to all channels on a card. Individually programmable voltage reference (Vref) and resistors R1 and R2 determine the balancing-current.

\section{Asynchronous vs. Synchronous}

In an asynchronous recycling-integratorthe balancing source fires as soon as the threshold is reached. During each charge-balance cycle the total net charge returns to zero and the output frequency varies continuously. For instance, $750 \mathrm{KHz}$ would be output as one pulse every $1.33 \mu \mathrm{s}$. In a synchronous design the balancing-sourcecan only fire when clocked. Since the balancing-source has to wait for the clock, the charge may not get completely balanced within one cycle and will carry over into the next charge-balance cycle; it can take multiple cycles for charge to balance. See [3] for a good description. The fi-equency varies in discrete steps. In this case, $750 \mathrm{KHz}$ would be output as 3 pulses spaced lis apart repeating every $4 \mu s$.

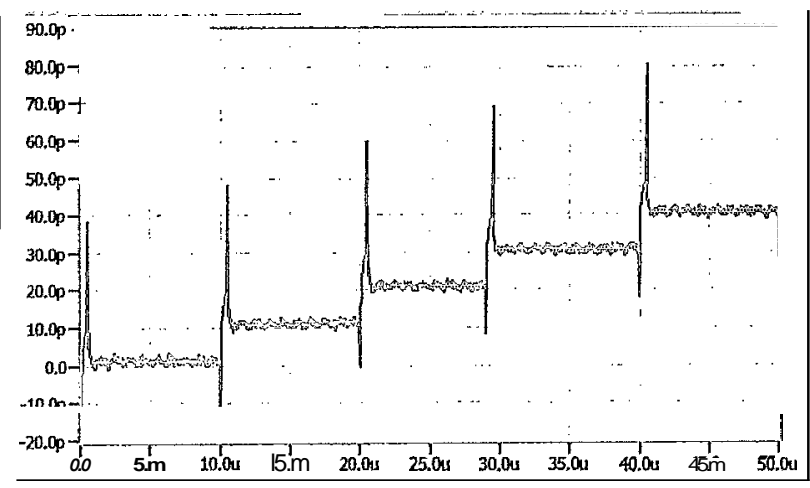

Figure 3: $10 \mathrm{pC}$ steps for $10 \mathrm{us}$ spacing

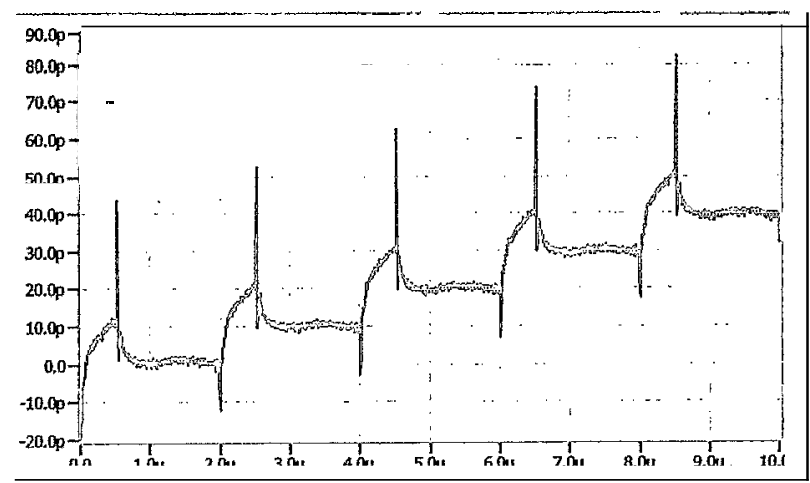

Figure 4: $\sim 9.8 \mathrm{pC}$ steps for $2 \mathrm{us}$ spacing

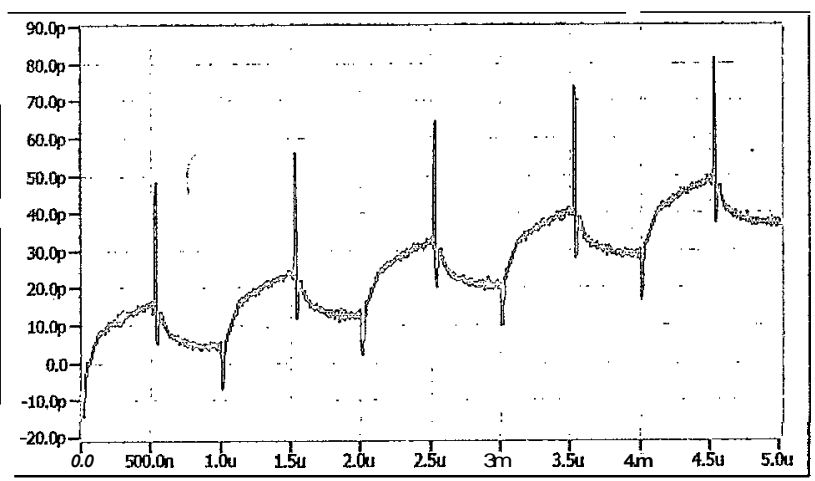

Figure 5: $\sim 8 \mathrm{pC}$ steps for lus spacing 


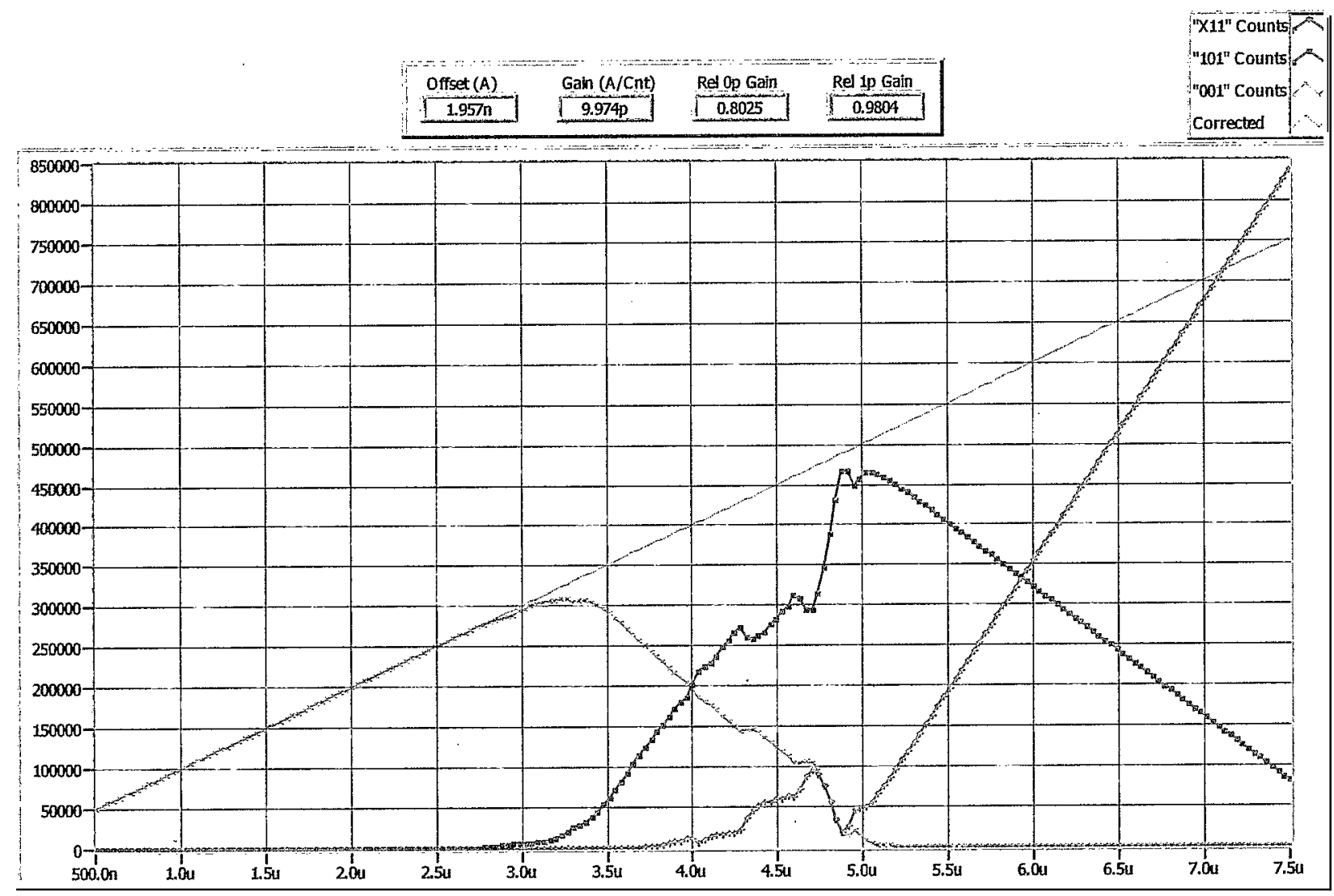

Figure 6: X11, 101, 001 pattern counts; the dashed line is the corrected response.

\section{Non-Linearity}

Figures 3 to 5 show that the effective charge-steps delivered by the balancing source decreases as the pulses become closer spaced. At $1 \mu \mathrm{s}$ (fig. 5) they no longer look like steps. What makes linearization possible is that the circuit itself is still operating linearly; the effect of the input current is independent of the effect of the balancing source and superposition still applies. Figure 3 to 5 were generated from the measured integrator voltage minus the assumed ideal integration of the calibration source.

The discrete nature of synchronous recycling-integrator causes the non-linearity to set in earlier than an equivalent asynchronous design. However, since the non-linearity is caused by the switching action and the timing is fixed, the discrete nature also provides the information need to correct the linearity.

\section{BIT-STREAMLINEARIZATION}

A synchronous recycling-integrator is also a first-order delta-sigma modulator and the output is then a bit-stream: 1 for a pulse, 0 otherwise. A repeating 0111 pattern is then another way to represent the $750 \mathrm{KHz}$ output. In this notation the rightmost bit is the present bit; the bits to the left are the previous samples. By interpreting the bitstream it's possible to correct the linearity. Pulses that arrive without a pause (11 pattern) only deliver $\sim 8 \mathrm{pC}$ per pulse. If only one pause separates pulses (101 pattern), then $\sim 9.8 \mathrm{pC}$ is delivered. If these factors are applied to the repeating 0111 pattern, then the correct current can be determined. The pattern produces one match to the 101 pattern and two matches to the 11 Pattern, or $9.8 \mathrm{pC}+$ $2 \times 8 \mathrm{pC}=25.8 \mathrm{pC}$. Over the $4 \mathrm{uS}$ period this is equivalent to a current of $6.45 \mu \mathrm{A}$, which agrees with figure 1 .

\section{FPGA Based Linearization}

A 20-bit accumulator was added to the FPGA to keep track of fractional counts. Depending on the pattern a relative gain factor for 0-pause or 1-pausepulse is added: typically .8 or .98 respectively. The actual values vary from channel to channel and are stored in registers. Figure 6 shows the resultant correction.

\section{CONCLUSION}

This solution is able to linearize the recyclingintegrators over their full range to less than $0.07 \%$ error. Lowering the sampling clock to $700 \mathrm{KHz}$ could reduce the linearity-errorbut not to this extent.

\section{REFERENCES}

[1] "NSRL Manual," pp. 19-23.

[2] J.R. Alonso, et al, "Operations Experience at the BEVALAC Radiotherapy Facility," in PAC' 81,1981 , p. 2827.

[3] Analog Devices, "AD652 - Monolithic Synchronous Voltage-to-Frequency Converter," Rev. C, 2004, pp. 6-8. 